\title{
Judicial construction and technical expertise as a means of protecting the interests of participants of building process
}

\author{
Andrey Butyrin ${ }^{1,2}$ and Ekaterina Stativa ${ }^{1,2, *}$ \\ ${ }^{1}$ Moscow State University of Civil Engineering, Yaroslavskoe shosse, 26, Moscow, 129337, Russia \\ ${ }^{2}$ The Russian Federal Center of Forensic Science of the Ministry of Justice, Hohlovsky Pereulok, \\ 13/2, 109028, Moscow, Russia
}

\begin{abstract}
The paper defines the significance of judicial construction and technical expertise as a means of protecting the rights and interests of participants of building process when considering and resolving economic and industrial disputes, significant number of which is based on the imperfect legal regulation of public relations of this activity. Noting the insufficient knowledge of the judicial community about the informational potential of this kind of judicial expertise, the authors presented a wide range of types of studies conducted by the building expert in practice. The presented list includes the following types of studies of the object of judicial construction and technical expertise: establishment of its existence; location; technical condition; its properties; qualitative and quantitative characteristics; cost; an object's belonging to a particular class, sort, kind, type, group; establishment of the conformity of its characteristics to a certain standard, rule or regulation. Consideration is also made of studies that have been conducted in judicial and investigation expert practice aimed at establishing the presence and types of causal connection between events that have been the subject of criminal investigation and (or) judicial proceeding, as well as establishing the object's existence by its representation, belonging of a part of the object to the whole, definition of a unified source of origin (manufacturer) of several objects of judicial construction and technical expertise.
\end{abstract}

\section{Introduction}

The purpose of this paper is to disclose the potential of the judicial construction and technical expertise (hereinafter referred to as the JCTE) as the most effective means of ensuring the protection of interests of participants of building process. Today, the Russian construction complex is the set of independent economic entities that have their own production and structural specifics that are not tied by systemic goals. Under the conditions of imperfect legal regulation of production relations and absence of developed competition among participants of building process, conflict situations are inevitable. Their consideration and resolution can occur in various procedural forms. Thus, the practice of

\footnotetext{
*Corresponding author: stativa@yandex.ru
} 
settling disputes, which arise out of civil legal relations that occur in the area of construction between economic entities, with the participation of an intermediary (during the mediation procedure) is beginning to emerge. The consideration and resolution of these disputes in the procedure of arbitration is gaining an increasing development. However, the most common form of protection of violated or contested rights and legal interests of citizens, as well as persons conducting the entrepreneurial and other economic activities in the area of construction, is the legal proceedings in arbitration courts and courts of general jurisdiction in civil and criminal cases.

Proper and well-timed resolution of production disputes is impossible without special construction and technical knowledge. The most effective form of its use is the judicial expertise. Its production is conducted on the basis of the latest achievements of science and technology, on which the methods of expert study are based, meeting the requirements of modern legal proceedings.

At the same time, the judiciary is not sufficiently informed about the scientific potential of the construction and technical expertise and, as a result, about its informational potential.

In order to fill this gap, firstly it is necessary to identify and present as completely as possible the list of types of studies conducted by a judicial building expert. They require detailed consideration.

\section{Research}

During the development of the theory and practice of judicial expertise (the first half of the 20th century), the notion of the multiplicity of types of judicial expert studies underwent certain changes. At the first stage of the formation of the conceptual framework of judicial expertise, they were divided into identification and non-identification, which was eventually found to be unproductive from the scientific point of view because the notion of "non-identification" did not disclose the essence of such studies, as well as any definition based on denial. In the second half of the 20th century, the classification system was formed including identification, diagnostic, classification, situational and cost study. This same system remains relevant to the general theory of judicial expertise today. Judicial construction and technical expertise, being rather specific kind of judicial expertise in its broad sense, required the rethinking of common (traditional) classification approaches and further work aimed at their development. The results of this work are represented in this paper.

\subsection{Establishment of the existence of the object of expertise - existential studies}

Before investigating the object of expertise, it should be found, discovered.

Existential studies in a broad sense are aimed at establishing the existence of the object, have a goal to establish its reality. During such studies, the expert is guided by a hypothesis based on special knowledge about the existence of the object (for example, about the existence of "old" bricks at the bottom of the walls of the building under reconstruction) and the data on obligatoriness - the special rules establishing the necessity (or excluding the possibility) of the existence of specific objects in certain conditions and circumstances. The special rules mean a set of construction norms and regulations, fixed in instructions and other documents regulating the actions of persons directly or indirectly conducting the building work, the characteristics of pre-design survey works, design, construction, operation, reconstruction (repair) and utilization of buildings, structures and constructions, as well as establishing the requirements for building objects (their separate fragments) and territories functionally related to them. 
Thus, the basis, the motive for the solution of the existential problem can be either a hypothesis about the existence of some object, the signs of any event (occurrence, process) or a direct indication of the necessity for such existence in legislated norms and rules.

When solving the existential tasks of the JCTE, the data, which characterize one of the sides of the object of expertise, established by this type of study will be correlated with the provisions of special rules. For example, in the process of obtaining expert opinions in criminal cases related to accidents that occurred during the performance of work at altitude, the following points should be established depending on the circumstances: the presence of personal protective equipment (helmets, safety belts, overalls, etc.) on the victim; the presence of garbage, building materials, snow (ice cover) on the scaffolding; the presence of non-slip buffers (metal spikes, rubber tips, other stopping devices) at the portable ladders, etc.

Speaking about studies of this type, it should be noted that this kind of informational potential does not have the independent significance in most cases, i.e. after the existence of the relevant object is established, its specific sides, properties and relations are investigated for certain (other) purposes. For example, when establishing the existence of the object, its nature and belonging to a specific class (sort, kind) are established; it is stated that its characteristics do not comply with the current special rules (if any exists); the issue of the causal relationship between the existence (absence) of the object and the consequences that have occurred is often considered, as well as the issue of the relevance of this fact to the event under the study.

\subsection{Establishment of quantitative characteristics of the object of expertise - volumetric studies}

This type of study is aimed at the establishment of the types and volumes of work performed to resolve issues caused by changes in the characteristics of the construction object, that violate the terms of the contract. Volumetric studies include measurements and calculations aimed at establishing the quantitative characteristics of the construction performed. Such characteristics, for example, include the volume of constructed monolithic reinforced concrete structures (m3), the area of finishing premises (m2), the length of installed utility networks $(\mathrm{m})$, etc.

The volume of performed construction, installation and repair work is established by its instrumental measurement at the construction site. After it is compared with the records of the volume of work performed by the customer and the contractor, and the data contained in the design (estimate) documentation. The volume of concealed work (buried foundation, floor structures, roads, trenches with pipelines laid in them, etc.) is established according to the data represented in the concealed work acceptance certificate. In the absence of such certificates, the volume of work performed is counted according to the working drawings, as well as by unsealing of individual building elements and structures.

During the volumetric study, the building expert establishes:

- non-fulfillment and (or) performance of works in volumes that are less than that provided for by certificate of acceptance of work performed;

- absence of equipment provided for by the project documentation;

- replacement of materials and equipment with other materials and equipment;

- discrepancy of works performed with construction norms and rules;

- incompleteness of objects, separate stages of work.

\subsection{Establishment of qualitative characteristics of the object of expertise - attributive studies}


The experts often study the properties of products of construction production. These objects, like any material formations, have an infinite variety of properties, but only those that are important for establishing the truth in the matter become the subject of expert study. These are functional (designation properties), operational, aesthetic, consumer and safety properties. During the study, the expert must identify, study, evaluate certain attributes of the object and express his opinion about its properties. Defining the properties of the object under the study, the expert must proceed from the fact that it is characterized not only by the presence, but also by the absence of certain features.

In order to get a better idea of the properties of objects of the JCTE and the ways of their establishment, it seems rational to describe the most significant of them for expert practice.

Functional properties determine the purpose of the products of construction. They are formed already at the stage of manufacturing of building materials. Therefore, the expert starts the study from their examination, whether he has a task to determine the causes and conditions for the initiation and progression of destructive processes in the structure of the building, complete (partial) loss of functional properties of the premises or a separate element of the building structure.

Operational properties make it possible to use the object in accordance with its functional purpose. The operating procedure of buildings provides for "consumption of constructed facilities", i.e. the use of their premises, systems, surrounding territories for the certain purposes. In the case of a residential building, the right operation means the use of apartments for living of citizens, the needs of which can only be met if all engineering systems function smoothly, premises have the certain dimensions, the certain level of noise is provided, insolation and illumination are provided, etc.

Safety properties. These properties should include, for example, the reliability of equipment. It is provided already at the stage of constructional design, and then at the manufacturing, taking into account the mechanical, thermal and chemical effects which will affect the equipment in the process of operation. In addition to the strength characteristics of machines and mechanisms, that determine their ability not to fracture and, therefore, not to injure people, it is necessary to keep in mind the hazards that are created during the operation of proper functioning equipment, for example, moving parts of machines, moving loads, noise, vibration, etc.

Under the aesthetic properties of buildings, structures and constructions is understood their architectural expressiveness. It corresponds to the purpose of the construction objects and manifests in the rationality of the forms, the wholeness in the composition and the perfection of implementation of the construction and decorative works, both separate building and the general urban planning composition of the building ensemble. Aesthetic requirements are also applied to individual elements of the interior fit-out of housing and industrial premises - finishing the surfaces of the floor, walls, ceiling; sanitary and technical equipment, etc.

Consumer properties are the properties (objective features) of products of construction production, which determine its ability to meet the certain need in the operation process. Consumer properties are closely related to the properties of safety, functional, operational, aesthetic and others and determine the cost of products.

\subsection{Establishment of the identity of the object of expertise and its representation - identification studies}

So common in the performance of forensic (trace, ballistic, handwriting, etc.) expertise, identification tasks in the performance of judicial construction and technical expertise are extremely rare and very different from traditional identification studies. Also, the 
terminological differences in the conceptual framework of the construction and judicial expertise should be noted. Identification in construction means the same what the classification study means in judicial expertise, i.e. the establishment of the belonging of an object to the certain class, sort, kind, group, type.

The following studies are conducted within proceedings of the judicial construction and technical expertise in their judicial expert interpretation.

\subsubsection{Establishment of the identity of the object and its representation}

In the performance of forensic expertise, these studies are aimed, for example, at the establishment of the identity of the ridge patterns of a particular person and the prints of these patterns on various objects. By raising the question to the expert: "Is this particular building, structure or construction, or its part (fragment) represented in the project documentation, in photographs (including - aerial photography, surveying from space), diagrams, drafts or drawings?", the court orients expert to the establishing the identity between the existence of an object in reality and its representation in various forms on the basis of the evaluation of the complex of object identification attributes and perceptions about its identification properties.

Consequently, if one uses traditional forensic expert terminology, according to one system of concepts, a contentious building, structure or construction means here an identifiable object (i.e. the one whose identification constitutes the task of the study), and its images in various forms - identifying objects (i.e. objects by which this problem is solved).

\subsubsection{Establishment of the belonging of a part of the object to the whole}

When considering civil disputes about the ownership of a particular building object, the plaintiff or defendant argues his claim to it by the fact that the object is an element of the building complex (industrial, architectural, residential, etc.), which is already owned by him, in the absence of any other arguments (including those who have a documentary form). Consequently, the question is posed to the expert: "Is the contentious object an element of the construction complex?". Solving it, the expert establishes the presence (absence) of unity signs (architectural and planning, compositional, engineering and communication, technological, etc.) of the contentious object and the complex of other objects. As an example of this can be the following questions which are raised to the expert in practice: "Are the weir and earth-filled dam an integral technological part of the M5 motorway?"; "Are the weir and earth-filled dam the objects involved in the road traffic along the M5 motorway?" With the presence and sufficiency of such indicators, the expert states the belonging of the contentious object to the complex, in the absence of it - makes a perception that the object is independent and is not an element of the construction complex.

\subsubsection{Establishment of the identity of the object to itself during different periods of time}

Establishment of the identity of the object to itself during different periods of time is necessary in those cases when it is necessary to individualize this or that contentious building object, to emphasize it among similar ones located in the close proximity. This situation is characterized by the prescription of the construction of the contentious building object (or a part of it) and its changes (extensions, superstructures, changes in the external texture of the facade, etc.) with time. The identifiable object is the building object in its 
current state and appearance. And identifying objects - its representations (photographs, drafts, etc.) at different periods of time.

\subsubsection{Establishment of the unified source of origin of objects under the study}

In the theory of judicial expertise, such objects mean a certain number of uniform objects, which, because of the presence in them of features that are random for these circumstances, is different from the other mass of objects of the same kind, but of the different origin. Specific organization that has conducted a particular stage of building of the construction object or its capital (or other type) repair, expansion, reconstruction should be established during the trail. Today, there is no material judicial expert methodology that allows determining the prescription of construction works, as well as their executors. However, these circumstances do not always remain unidentified by the building expert. If during certain production operations the time (period of the past) can be established by examining the relevant documents (the log of the execution of certain type of work, certificates of acceptance of work performed, etc.) and the characteristics of used structures, products and materials allow identifying them, emphasizing them from a number of other similar ones, and the identification features are peculiar for particular producer (for example, manufacture enterprise), in which archives the copies of the accompanying documents on the goods to be supplied to a specific consumer are kept, indicating the dates of the goods expedition, then these data in the aggregate make it possible to determine the period (stage), the prescription of certain construction works, and in some cases, when various construction organizations performed work on the same object, to establish the executor of specific works. So, for example, according to the unified source of origin - the manufacturer of unique elements of interior decoration of premises and accessories produced and delivered to the construction facility in a certain (documented) period of time, was established by the expert as a specific performer of repair and recovery works. Also, the prescription of conduction of these works was established.

\subsection{Establishment of relative position of the objects of expertise - situational studies}

The solution of the situational tasks is aimed at the establishment of relative position of the objects of expertise or their individual components and determination of the characteristics of the events, occurrences, actions and processes of which they are the elements.

When courts consider claims for recognition of building unauthorized on the basis that its construction was conducted with significant violations of urban planning and building regulations and rules, the expert determines the distance from the newly constructed (contentious) building, structure or construction to previously constructed building objects or objects of high bacteriological risk (landfills of household and other waste, toilets, etc.). In the first case, the compliance of new construction with the requirements of fire safety regulations should be verified, in the second - sanitary regulations. These studies also fall into the category of situational ones. If they are divided into macro- and micro-studies, then the studies mentioned above can be attributed to the first ones. In this case the second ones will be directed to the components of the object of expertise. It can be elements of the reinforcing cage of the reinforced concrete structure (relative position of the embedded parts and reinforcement bars), fasteners (their relative orientation to each other) of the joint unit of individual building structures made of glued laminated timber or polymer materials, etc. Taking into account the static character of the condition of the above-mentioned objects of expert studies, these tasks should be referred to the situational and circumstantial. 
The solution of the situational tasks is also aimed to the reconstruction of the real situation of the event that has occurred, allowing (using the results of other studies) to recreate later the nature and sequence of its individual fragments, which is the dynamic component of these studies. These tasks are related to situational and eventive.

\subsection{Establishment of the cost of the objects of expertise - value studies}

Studies related to the determination of the cost of work performed and the building materials used, the building object as a whole or a part of it, go beyond the expertise being considered. However, in practice, these studies have been and remain an integral part of the professional work of the building expert.

The purpose of expert determination of the cost of products of construction production or performed repair and construction works is to establish the circumstances that have an evidential significance. They need to be clarified for the correct resolution of the case. The consequences of stopping the construction should be attributed to the circumstances of this kind. According to Article 752 of the Civil Code of the Russian Federation [1] "if the works under the construction contract have been suspended and the construction site has been mothballed due to the reasons beyond the control of the parties, the customer is obliged to pay the contractor in full for the works performed up to the time when works have been mothballed. And also reimburse the expenses caused by the need to terminate works and mothball the construction, taking into account the benefits that the contractor received or could receive as a result of the termination of works." If the dispute between the customer and the contractor about this amount will pass to the area of the legal proceedings, the building expert will have to conduct the cost calculations. The necessity of such calculations arises in determining the cost of overspent materials in the course of construction work, since the unreasonable overuse of materials does not apply to the cost of construction work, but should be compensated by the guilty persons under the current statutory procedure.

Article 216 of the Criminal Procedure Code of the Russian Federation [2] provides for the criminal liability for violations of the rules of construction activity, which caused considerable damage. Determination of its value expression is only possible by using the appropriate special knowledge.

The cost of construction works is determined in accordance with the terms of the work contract, on the basis of current estimate norms, as well as on the basis of the provisions set out in the methodological documents of the construction sector. These provisions can be divided into two types.

The first type includes the following: state estimate norms, industry estimate norms and territorial estimate norms. These norms are the basis for the corresponding unit prices federal and territorial.

The second type includes firm and individual estimate norms.

The first type of cost calculations is characterized by the fact that the basis for determining the cost of construction works is the use of estimated federal territorial or industrial norms (the last two norms take into account the specifics of particular region or industry). The use of territorial unit rates is mandatory upon condition that the construction is financed from the regional budget. If financing is made from the federal budget or the terms of the contract provide for the use of federal estimate norms, then the cost is calculated using the federal unit rates. Estimates and normative bases, as well as the coefficients of cost conversion from the basic price level to the current (or for a certain period of the past), are periodically updated. Licensed software packages are used for compilation of estimates (for example: Smeta.ru, Grandsmet, etc.). 
The second group of estimate norms is characterized by the fact that they (firm and individual) are used in those cases:

- it's prescribed by the terms of the contract;

- state, industrial and territorial regulations do not regulate the procedure for calculating the cost of certain (specific) types of work.

In accordance with the current legislation, economic entities have the right (on the contractual basis and on the parity basis) to use any procedure for calculating the cost of construction, which corresponds to the actual conditions of work performance.

\subsection{Establishment of the belonging of the object of expertise to the certain class, type, kind, group - classification studies}

A common feature of classification studies is the establishment of the belonging of the object to the official set of objects (provided for by the state standard or other normative document), whose properties and characteristics are known in advance, on the basis of determination of its properties and characteristics.

The issue of the belonging of building products, parts, structures to products, details, structures of a particular class, type or kind is often raised to the building expert. For example, when determining the cost of masonry, it is necessary to determine its type simple, medium complexity, complex; when determining the causes and conditions of destruction of the building (construction) - the concrete grade and the class of reinforcement, the grade of the reinforced concrete structures and details, the type of soil on which the construction is conducted.

When identifying the defects of products of construction production or performed construction works, the building expert, depending on the nature of the defect, determines it as recoverable (capable of being amended) or as final, i.e. not capable of being amended. By the place of detection, the defect is subdivided into the internal one, identified by the construction organization before the handing over of work to the customer, and the external one, revealed during the operation of the construction object.

Particular classification of tasks of the JCTE includes the tasks of establishment of the belonging:

- products of the industry of building materials (details, products, structures) to the certain type, grade, class;

- products of construction production (buildings, structures, constructions) to the certain series, type of stability, area of operation (industrial, civil, etc.);

- buildings and structures to the group that involves the operation of objects in special conditions (seismic and mudflow danger, with a high level of groundwater, in a territory with unstable soils, etc.);

- conducted (planned) repair and construction works to the capital, current, preventive repair type, etc.

\subsection{Establishment of the state of the object of expertise - diagnostic studies}

The current understanding of technical diagnostics considers the object of study according to its negative change over the time and has a prognostic character. The study of objects for determination of possible future deviations from their operating condition is carried out by the building expert. During the solving of diagnostic tasks, the deviations from the requirements of building norms and rules regulating both design and construction can be established. Also it will be possible to reveal the signs that will allow establishing the initiation and progression of destructive processes in the structures of the building under the study - this may be evidenced by the presence of cracks, deflections, spalls, etc. The 
knowledge of the common factors of such processes will allow formulating a prognostic conclusion, for example: "Destruction of the building is inevitable under these conditions ". However, there are cases when there is no need for conclusions of this kind. For example, when considering claims for the recognition of a contract for the renting of residential accommodation invalid, expertise is being appointed. During this expertise only the presence (absence) of deviations from the sanitary norms that apply to the premises to be inspected is established. The conclusions will only contain the statement of some fact, for example, the fact of deviation from the standard value of the insolation level, lighting, noise. As a result, it will be established that the condition of the room under the study does not meet the requirements for residential accommodations.

In accordance with Part 1 of Article 754 of the Civil Procedural Code of the Russian Federation [1], the building contractor is liable to the customer for the deviations from the requirements provided for by the technical documentation and by the construction norms and rules binding on the parties. Also, during reconstruction (renovation, rebuilding, restoration and etc.) of the building or structure, the contractor is responsible for reducing or losing the strength, stability, reliability of the building, structure or a part of it. In that case, if the contractor judicially disputes the existence of deviations from the specified construction norms and rules, partial or complete loss of the listed properties by the construction object, then the JCTE will be appointed by the court. During this expertise, diagnostic task which is aimed only at the confirmation or refutation of the expected circumstances will be solved.

\subsection{Establishment of the presence and types of the causal connection between events, occurrences, actions and processes - causal studies}

The solution of this type of tasks is aimed to the establishment of the presence and types of causal connection between deviations from the requirements of special rules and various kinds of negative events (occurrences). Let's consider an example from the practice. In the proceedings of a civil case involving the collapse of the external brick wall of the building under construction, it was necessary to establish the cause of the collapse. Having studied the case files and examined the construction object, the expert came to the conclusion that the wall collapsed as a result of the foundation's mismatch with the type of soil which had a high unsteadiness. This property of the soil appeared after the rain and the wall which did not have the proper support tilted. As a result of deformation of the soil under the foundation, the tilt became so significant that it went beyond the stability of the structure, and this led to the collapse of the wall. With further study of the case files by the expert, it was established that the structure with the foundation that did not correspond to the geological report, was constructed without the obligatory development of the soil investigation project. Thus, the definition of the causal connection has played a key role in the establishment of the truth in the case.

Determining the causes of different events, the expert should divide the concepts "cause" and "condition", proceeding that the cause is an active process, occurrence or action. The condition is the static situation in which the process, which was the cause, took place.

For example, if in the course of excavation the working electric cable was damaged and the excavating machine was damaged by the electric current, then the nearest "technical" cause of the event is the mechanical, destructive effect of the working part of the machine on the protective casing of the electric cable, the propagation of the electric current on its conductive elements. The very fact of finding the working electric cable in the excavation zone should be considered as one of conditions of the incident. 
In that cases, when the existence of the causal connection is only assumed (any expert task contains an element of uncertainty), the task of expert study will be to establish the presence (absence) of this connection.

The cases of claims for compensation of damages caused by the pernicious influence of the construction industry on the environment and human health have become increasingly common. Judicial inquiry of the cases of this category is impossible without the use of special knowledge in the field of both construction and ecology and, therefore, without the appointment of a comprehensive expertise. The task of the building experts in such cases is to establish the fact of conducting of all the necessary measures aimed at excluding the negative influence of the construction object on the nature, to reveal all deviations from the requirements of special rules regulating the order and sequence of work performance. For his part, the environmental expert can establish the fact of the initiation and progression of processes harmful to the nature and human. Their common task will be the establishment of the causal connection between the revealed deviations and the consequences that have occurred.

\subsection{Establishment of conformity of the object of expertise to any norm or rule - normative and deviant research}

The tasks of this type are aimed at the establishment of the conformity (or absence of it) to the requirements of special rules (norms, regulations) of the actions of persons (or the results of these actions, for example, products of production) directly or indirectly participating in the production operation, either during or after which occurred an event that has been the subject of an investigation or a judicial proceeding. The process of comparing the existent and the due is indicative for them; their distinctive feature is the existence of a norm (the state of a special rule) in the system of elements of comparison.

Normative and deviant tasks are most often formulated as follows: "Were there any deviations from the requirements of special rules in the performance of those jobs during which an accident occurred?" Or "Did the requirements of special rules contradict the presence of a pallet with bricks on the edge of a balcony without guard rails (storage of timber at the edge of the ditch)? "; "Did the mounting joint connecting the slab and the outer wall conform to the requirements of building norms and rules?".

Questions of this kind orient the expert to establish the conformity of actions of persons (for example, participants of building process) to the requirements of building norms and rules regulating work safety issues or the procedure for performing certain production operations and technological processes.

\section{Results}

The studies conducted as a part of the performance of the JCTE can be represented by the following list:

establishment of the existence of the object of the JCTE in specific conditions, studied by an expert - existential tasks;

establishment of the quantitative characteristics of the construction - volumetric tasks; establishment of the properties of the object of the JCTE - attributive tasks;

referring the part of the object to the whole (establishing the belonging of the building to the architectural or production complex), establishing the identity of the object and its representation (correlating the actual building object and its representation in the design documentation and other documents), determining the unified source of origin (production) of the objects under the study (establishing the manufacturer of structures, products and materials) - identification tasks; 
establishment of the sequence, duration and nature of individual fragments of the event which has become the subject of judicial proceedings; the determination of the parameters of the relative positions of the objects of the JCTE and their individual fragments, which are relevant for the case - situational tasks;

determination of the cost of performed construction works, as well as other special works, the cost of buildings, structures, constructions, their individual fragments, as well as the territory (land plots) functionally related to them - value tasks;

establishment of the belonging of the object of the JCTE to any class, type, kind, group - classification tasks;

establishment of the conformity of the characteristics of the object of the JCTE or the process, technological operation, actions to certain norms, rules, standards, regulations normative and deviant tasks;

establishment of the state of the object of the JCTE - diagnostic tasks;

establishment of the existence and type of causal connection between deviations from the requirements of special rules regulating the processes of construction production and operation of construction facilities, and the consequences that have become a subject of judicial proceedings - causal tasks.

\section{Discussion}

In the theory of judicial expertise, the issue of the classification of judicial and expert studies has a polemical character. The starting point of the discussion is the content of the concept of "diagnostic judicial and expert studies". In accordance with one point of view, the interpretation of this concept should be wide enough and includes the establishment of the state of the object, its properties, as well as the causes and mechanisms of events, processes, actions and occurrences in which the object of expert study was involved.

From another point of view, the narrowest interpretation of the concept under consideration is preferable, i.e. diagnostic studies should be understood only as the establishment of the state of the object of expertise.

The authors of this paper prefer the narrow interpretation of the contentious concept, arguing that the unification under different names of different informative acts does not contribute to understanding their specificity and, consequently, to their development and improvement. Narrow interpretation allows distinguishing the attributive, causal and situational event studies into individual types. It fully represents the diversity and specificity of studies conducted as a part of judicial construction and technical expertise and contributes to its improvement and development in both theoretical and practical aspects.

\section{Conclusions}

In our opinion, this detailed list of types of studies makes it possible to disclose the specifics of each of them. This creates prerequisites for further deeper theoretical and methodological study, further development and improvement of the practice of performing the construction and technical expertise.

The detailed consideration of the studies demonstrates the informational potential of this kind of applied activity, makes it more accessible to the judicial community and provides it with the opportunity to take full advantage of the expert's special knowledge. All of this creates the basis for increasing the efficiency of modern legal proceedings in general, one of the goals of which is to protect the rights and legitimate interests of participants of economic activity, including construction. 


\section{References}

1. Federal law № 138-FZ of November, 14 (2002)

2. Federal law № 174-FZ of December, 18 (2001)

3. A.Yu. Butyrin, Sudebnaya stroitelno-tehnicheskaya ekspertiza (Moscow State Construction University, Moscow, 2014)

4. A.A. Eisman, Zakluchenie eksperta (struktura i nauchnoe obosnovanie) (Legal Literature, Moscow, 1967)

5. A.Yu. Butyrin, Opredelenie technicheskoy vozmozhnosti I razrabotka variantov preobrazovaniya zhilogo doma kak elementa domovladeniya $v$ sootvetstvii $s$ usloviyami, zadannymi sudom: metod. Rekomendatsii dlia ekspertov, Collection of Methodological Recommendations on Judicial Construction and Technical Expertizes Procedure (FBU RFTsSW at the Justice Ministry of Russia, Moscow, 2012)

6. Metodika opredeleniya fizicheskogo iznosa grazhdanskih zdaniy (RSFSR Ministry of Public Utilities, 1970)

7. Osnovy sudebnoy ekspertizy (Russian Federal Center of Forensic Enquiry at Justuce Ministry of Russian, Moscow, 1997)

8. Z.M. Sokolovskiy, Ekspertnoe issledovanie prichinnoy sviazi po ugolovnym delam (RIO Ministry of Internal Affairs of the Ukrainian SSR, Kiev, 1970)

9. Z.M. Sokolovskiy, T.N. Cherepovskaya, Expert Practice 13, 27-34 (1962)

10. Z.M. Sokolovskiy, Problema ispolzovaniya v ugolovnom sudoproizvodstve spetsialnyh znaniy dlia ustanovleniya prichinno-sledstvennoy sviazi yavleniy, D.J.S. thesis, (Kharkov Scientific - research institute of forensic examinations them, Kharkov, 1968)

11. P.J. Murphy, L. Duthie, B. Bielert, D. Charrett, Australian Journal of Structural Engineering 11, 1 (2010)

12. R.K. Noon, Applications in Failure Investigation and Forensic Science (CRC Press, 2009) 